Research Article

\title{
Genre Analysis of Research Article Abstracts in English for Academic Purposes Journals: Exploring the Possible Variations across the Venues of Research
}

\author{
Mavadat Saidi $(\mathbb{D})$ and Said Talebi \\ Shahid Rajaee Teacher Training University, Tehran, Iran \\ Correspondence should be addressed to Mavadat Saidi; m.saidi@sru.ac.ir
}

Received 9 April 2021; Revised 6 June 2021; Accepted 8 June 2021; Published 14 June 2021

Academic Editor: Ehsan Namaziandost

Copyright (c) 2021 Mavadat Saidi and Said Talebi. This is an open access article distributed under the Creative Commons Attribution License, which permits unrestricted use, distribution, and reproduction in any medium, provided the original work is properly cited.

\begin{abstract}
Research article (RA) abstracts play a pivotal role in settling the fate of the academic papers. Despite the abundance of research on investigating the generic structure of this academic genre, the variations in its move patterns between the two venues within a single area of research seem to have remained untouched. The current study attempted to explore the constituent moves and move patterns of RA abstracts published in a local (Iranian Journal of English for Academic Purposes) and an international (The Journal of English for Academic Purposes) journal in the field of applied linguistics. Drawing on Hyland's (2000) five-move model, the RA abstracts were analyzed. The results indicated that the abstracts published in the two journals included the conventional moves. Furthermore, the most frequent moves were the purpose, method, and product in the two corpora. Moreover, although the results of the chi-square test pointed to no significant difference in terms of the frequency of the moves in the abstracts, the analysis divulged variations in the move patterns across the two sets of articles. The findings carry pedagogical implications for the academic writing course designers, materials developers, and instructors to enhance the novice researchers' familiarity with the writing conventions to facilitate their accommodation by the scientific communities.
\end{abstract}

\section{Introduction}

To meet the requirements of the academic discourse communities, English as a Foreign Language (EFL) learners need to gain a good command of the English language for completing various academic tasks [1]. On the other hand, researchers are growingly required to publish their research findings in highly prestigious and refereed journals in the field in order to get promoted in their academic and professional communities [2]. In this regard, knowledge of genre contributes to building up and boosting their confidence to present the results of their research projects [3]. Indeed, being cognizant of the rhetorical structures of a research article (RA) empowers the novice members to comply with the existing writing conventions and thereby facilitates their accommodation in their scientific communities $[2,4]$. These pedagogical implications for English for
Academic Purposes (EAP) courses led to the undivided attention paid to genre analysis in applied linguistics [5].

Among the available genres and subgenres in academic discourse, abstracts as the screening devices [6] for determining the ultimate decisions for accepting or rejecting the research articles stand out [7]. Most non-native authors confront difficulties in writing academic texts that fulfill the expectations of international reviewers and editorial boards [8]. Knowing the constituent generic patterns of such an important genre raises the EFL learners' consciousness about the existing discursive norms [9].

Abstracts put the authors in the right locus for presenting the synopsis of their research [10] and parading the novelty of their work [11]. Indeed, research article (RA) commercialization commences in this genre. Demanding a tactful way of presenting the summary of the research procedures and products, writing abstracts seems to be a 
tough task for the non-native members of academic communities [12]. These all lead to the call for analyzing the generic structure of RA abstracts in the existing literature [13].

Given the importance of the RA abstract as a significant scholastic enterprise [14], numerous frameworks have been proposed to unravel its generic pattern [15-18]. Among the proposed models, Hyland's [18] five-move model seems to provide a comprehensive framework covering introduction $(\mathrm{I})$, purpose $(\mathrm{P})$, method $(\mathrm{M})$, product $(\mathrm{Pr})$, and conclusion (C) [19]. Moreover, the model is grounded on analyzing the genre of 800 abstracts in eight disciplines in both science and social sciences [20].

In this regard, a large number of studies have focused on analyzing the genre of abstracts across various disciplines and languages [13]. The previously conducted studies have mostly focused on the generic structure of the RA abstracts adopting a cross-linguistic and cross-disciplinary approach. Few studies $[2,21]$ have attempted to unravel the variations they may witness across various venues of research in one particular discipline. Indeed, understanding the possible variations in interpreting the academic textual norms at the local and international scales seem to contribute to the novice members' socialization [2]. It is claimed that academic discourse communities follow a fixed, impartial set of conventions regardless of the researchers' individual backgrounds and violating these norms may result in ejecting them from the community. This seems to put the non-native researchers in a predicament [9].

Given the significant role of the abstract in settling the ultimate fate of the RAs and bearing in mind the sparse literature on analyzing the generic structure of RA abstracts across various journals, El-Dakhs [2] called for conducting genre analysis of the RAs in more and less prestigious journals in various disciplines and subdisciplines. To respond to this recent call for further studies on this dimension of the academic genres, the current study aimed to see to what extent RA abstracts published in two different venues would comply with Hyland's [18] model. In this regard, English for Academic Purposes as the cradle of genre analysis was considered and two venues of publishing papers in this subdiscipline of applied linguistics were considered, namely, the Journal of English for Academic Purposes (JEAP) and Iranian Journal of English for Academic Purposes (IJEAP), to see if their abstracts would significantly differ in terms of the constituent moves. Accordingly, the study attempted to address the following questions:

(1) Are there any significant differences across RA abstracts in the JEAP and IJEAP in terms of the constituent moves?

(2) Are there any significant differences across RA abstracts in the JEAP and IJEAP in terms of adopting the move structure of Hyland's [18] model?

\section{Literature Review}

Abstracts as "a major scholastic enterprise" (14:2) allow the academic audience to decide upon acknowledging the full paper [12]. To analyze the generic constituents of the abstracts, various models have been proposed. Swales [15] put forth the Introduction-Method-Results-Discussion (IMRD) framework. Bhatia [16] redefined and categorized the moves into four major ones, namely, introducing purpose, describing methodology, summarizing results, and presenting conclusions. Adding a move to the previously identified ones, Santos [17] presented a fivemove model encompassing situating the research, presenting the research, describing the method, summarizing the results, and discussing the results. Likewise, Hyland [18] provided a five-move model including introduction, purpose, method, product, and conclusion (IPMPrC).

A host of studies have revealed the generic patterns of RA abstracts using Hyland's [18] model. In this regard, Saeeaw [22] explored the moves of RA abstracts in environmental science and applied linguistics and found out that the authors of both groups of abstracts made more use of four moves, excluding the introduction move. In another study, Sidek, Mat Saad, and Idris [23] analyzed the moves of conference proceedings abstracts in linguistics and applied linguistics and demonstrated that purpose, method, and product moves were the most frequently used ones. In the same line, Darabad [24] compared the constituent moves of the abstracts in three fields of applied linguistics, applied mathematics, and applied chemistry and demonstrated the highest frequency of purpose and product moves.

In a seemingly different line, El-Dakhs [2] analyzed the genre of abstracts in the field of linguistics in the two corpora including less prestigious and more prestigious journals using Hyland's [18] model and found out the general conformity of the RA abstracts to the move pattern in the used framework. The findings demonstrated 38 and 35 varied move patterns in the abstracts of less and more prestigious journals, respectively. Also, it was shown that the abstracts in less prestigious journals included the lengthier introduction, purpose, and method moves while the authors of more prestigious journals highly focused on presenting the findings of their research and provided longer product moves in the abstracts.

In another study, focusing on the journals of applied linguistics published in Oxford and the Islamic Azad University of Tabriz, Behnam and Zamanian [21] adopted Swales's [15] model and analyzed the generic structure of RA abstracts. They found out discrepancies between two groups of abstracts in terms of the results and method moves and demonstrated that the abstracts in both corpora included the introduction move. It was also shown that the authors of the applied linguistics journal of Oxford used results and methods moves less than their counterparts who published their abstracts in the applied linguistics journal of Tabriz.

Taking prior research altogether, it seems that the generic structure of the abstracts across different venues of research has not received its deserved attention [21]. Furthermore, the parallel local and international journals in the field of applied linguistics have scarcely been analyzed [2]. To fill this void, the current study focused on the generic structure of the abstracts published in a local and an 
international journal on English for Academic Purposes (EAP).

\section{Method}

3.1. Corpus. The corpus consisted of 171 RA abstracts published in two journals on English for Academic Purposes (EAP). To prevent the corpus to be contaminated by the influence of time of publication [25], only the abstracts published between 2019 and 2020 were considered. Moreover, attempting to ensure the homogeneity of the corpus, the original research papers were included for analysis [4]. Hence, 55 research articles were selected from the Iranian Journal of English for Academic Purposes (IJEAP) and 116 articles were selected from the Journal of English for Academic Purposes (JEAP). IJEAP is an academic scholarly journal published by Chabahar Maritime University in Iran and is a forum for disseminating theory- and practice-oriented research related to EAP; it is indexed in ISC. JEAP is an international journal published by Elsevier and allows the researchers to present their findings related to EAP themes.

3.2. Data Analysis. Hyland's [18] five-move model was utilized to analyze RA abstracts. The model provides a comprehensive framework covering introduction (I) (which provides the required background for the topic under the study), purpose $(\mathrm{P})$ (which outlines the goals and presents the research questions and hypotheses), method $(M)$ (which elaborates on the design, procedures, and instruments used in the study), product (Pr) (which reports the major findings), and conclusion (C) (which presents the applications and implications based on the findings) [19]. In order to identify the conventional and optional moves, the researchers drew on the existing literature. In this sense, the moves with the frequency of occurrence above $60 \%$ were considered as the conventional ones and the ones with less than this amount were referred to as optional.

The RA abstracts were analyzed in terms of their constituent moves by the two researchers and an intercoder reliability of 0.98 was obtained. Whenever disagreement arose, they negotiated till reaching a consensus. Descriptive statistics were used and frequency and percentage values were presented for each move in the two corpora. Moreover, to see if there was a statistically significant difference between the two groups of abstracts in terms of their moves, the nonparametric test of chi-square was run.

\section{Results and Discussion}

4.1. Move Occurrence. In order to identify the moves of the RA abstracts in the two corpora, Hyland's [18] model was used. Table 1 displays the frequency and percentage values of moves in RA abstracts published in IJEAP and JEAP.

As the results indicate, $34 \%$ and $21 \%$ of the abstracts followed the conventional move patterns in the IJEAP and JEAP, respectively. This confirmed the results of EL-Dakhs's [2] study which demonstrated the conformity of the RA abstracts in both less and more prestigious journals in the field of linguistics to Hyland's [18] five-move model.
TABLE 1: Frequency and percentages of moves in abstracts.

\begin{tabular}{lcccc}
\hline \multirow{2}{*}{ Moves } & \multicolumn{2}{c}{ IJEAP } & \multicolumn{2}{c}{ JEAP } \\
& $\mathrm{F}$ & $\mathrm{P}(\%)$ & $\mathrm{F}$ & $\mathrm{P}(\%)$ \\
\hline Introduction & 38 & 70 & 80 & 68.96 \\
Purpose & 53 & 96 & 110 & 94.82 \\
Method & 51 & 93 & 105 & 90.51 \\
Product & 52 & 94 & 102 & 87.93 \\
Conclusion & 40 & 72 & 93 & 80.17 \\
Total & 234 & & 490 & \\
\hline
\end{tabular}

The comparison of the frequency of each move demonstrated the high occurrence of the purpose, method, and product moves in both groups of abstracts. In this regard, the results confirmed those of Sidek et al. [23] who showed the inclusion of these three moves in the RA abstracts in the applied linguistics and linguistics. This might imply the authors' cognizance of the crucial role of these three moves in drawing the scholarly readers' attention to the full paper [13]. Moreover, the findings were commensurate with Santos's [17] results which revealed the obligatory nature of these moves in applied linguistics abstracts. Nevertheless, the results were at odds with those of EL-Dakhs's [2] study which revealed discrepancies between the less and more prestigious journals in terms of the constituent moves of the abstracts.

Furthermore, the lower frequency of occurrence belonged to the introduction and conclusion in the abstracts of the two journals. The results corroborated those of Behnam and Zamanian's [21] study which pointed to both Iranian and non-Iranian authors' inclination to include the introduction move in applied linguistics RA abstracts. However, the results contrasted their study in that they demonstrated the low frequency of the occurrence of the conclusion move in their corpora. With regard to these two moves, the findings of the current study might signify the authors' tendency to take heed of presenting the topic and the existing void before articulating the purpose of the study [13]. Besides, the authors of the abstracts in both IJEAP and JEAP preferred to reckon with the implications of their research findings.

On the other hand, the authors' focus on including the introduction move in almost three quarters of the RA abstracts in the two journals seemed to be justified by the emerging nature of the EAP as an area of research in the broader subdiscipline of English for Specific Purposes (ESP) in the field of applied linguistics [25]. The results approved those of Atai and Habibie's [25] study which referred to ESP as an emerging subdiscipline, which may account for necessitating the presentation of some background to the target audience through including the introduction move.

Also, in the RA abstracts in both IJEAP and JEAP, the purpose move enjoyed the highest frequency of occurrence. This opposed the findings of the previous comparative studies $[2,21]$ which pointed to the dominance of other moves in the corpora drawn from different journals in the field of linguistics and applied linguistics.

To see if there was any statistically significant difference between IJEAP and JEAP RA abstracts in terms of their 
TABLE 2: Results of chi-square test.

\begin{tabular}{lllr}
\hline Chi-square test of independence & Value & df & \\
\hline Introduction & 0.667 & 1 & \\
Purpose & 0.005 & 1 & 0.41 \\
Method & 0.021 & 1 & 0.94 \\
Product & 0.049 & 1 & 0.88 \\
Conclusion & 1.600 & 1 & 0.82 \\
\hline
\end{tabular}
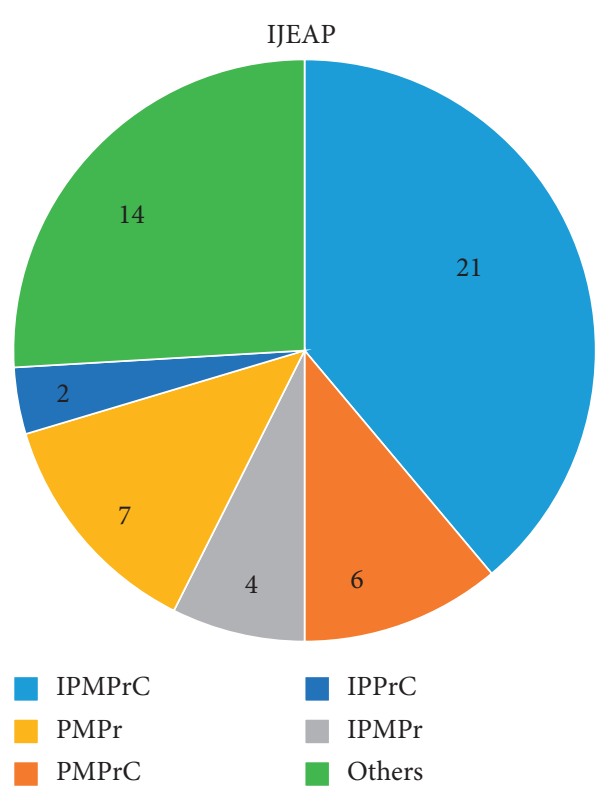

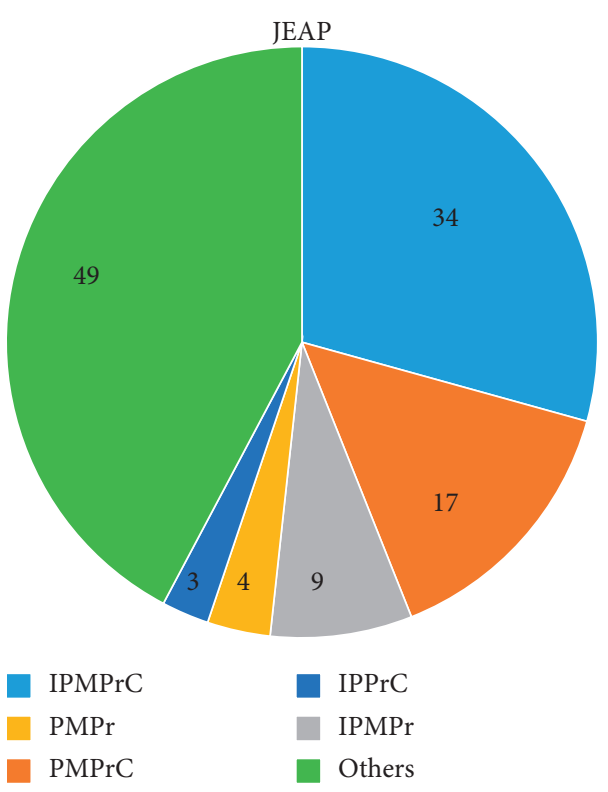

Figure 1: Percentage of the most frequent move patterns in IJEAP and JEAP. constituent moves, the chi-square test was conducted (see Table 2).

According to Table 2, no significant difference was observed between the two corpora. This might indicate that the authors of both groups attended to the generic norms existing in their academic discourse community and observed the generic rules governing the RA abstracts.

4.2. Move Patterns. The current study also attempted to explore the most frequent move patterns in the two corpora. As Figure 1 illustrates, the frequent move patterns were IPMPrC, PMPrC, IPMPr, PMPr, and IPPrC in both IJEAP and JEAP RA abstracts.

In general, the RA abstracts in IJEAP encompassed 19 move patterns and those in JEAP included 54 move patterns. Hence, it can be inferred that the generic structure of abstracts had $34.54 \%$ and $46.55 \%$ variation in IJEAP and JEAP, respectively. This may point to the various generic norms within a single subdiscipline across different venues of research. The authors in the two corpora omitted and/or combined some of the moves and generated a wide range of move patterns to make the most use of the limited space provided for presenting a synopsis of their study. This might underlie the authors' intentional discursive practices to highlight specific parts of their study [13].

\section{Conclusions and Implications}

The present study aimed to explore the generic patterns of RA abstracts in two journals on EAP, namely, the Iranian Journal of English for Academic Purposes and the Journal of English for Academic Purposes. The study strove to see whether the RA abstracts published in two venues of research, one local and one international journal, had variations in terms of their constituent moves. To analyze the collected corpora from the archive of the two journals, Hyland's [18] five-move framework was utilized. The results indicated that the abstracts in both corpora included the conventional moves. Moreover, the most frequent moves in both groups of abstracts were the purpose, method, and product. However, the introduction and conclusion moves were also considered and included in the abstracts, albeit to a lesser degree compared to the other moves. Despite the variations in the move patterns of the RA abstracts in IJEAP and JEAP, the results of the chi-square test revealed no significant difference between the two groups of abstracts in terms of the frequency of five moves.

The findings of the study can be converted into pedagogical principles for EAP teaching practices to raise the graduate students' awareness of the existing variations and generic norms of the RA abstracts in their field of study, particularly for those whose area of interest includes EAP 
and its current research and practice. Drawing on the results of the current study, incorporating genre-based activities and tasks in academic writing syllabi and materials is recommended to familiarize the novice members and researchers with the conventions of academic writing and facilitate their accommodation by the scientific communities $[2,4]$. In this sense, the findings of the study can be used to provide special genre-based training to those researchers craving for publishing their academic research findings in prestigious and refereed journals in the field.

The current study aimed at investigating the generic patterns of the RA abstracts in two refereed journals on EAP. Further studies may focus on analyzing the genre of the abstracts published in different journals in other areas of research, subdisciplines, or fields of study. Moreover, a contrastive genre analysis of the abstracts published in English and other languages may be conducted to see if the authors' preferences for including different moves would vary addressing different groups of the academic audience at the local and global levels.

\section{Data Availability}

The data used to support the findings of this study are available from the corresponding author upon request.

\section{Conflicts of Interest}

The authors declare that they have no conflicts of interest.

\section{References}

[1] C. M. Gessesse, "An investigation into the macro rhetorical structures of the EFL research abstracts of graduates of 2013: the case of Bahir Dar University in Ethiopia," Online Journal of Communication and Media Technologies, vol. 6, no. 1, pp. 1-22, 2016.

[2] D. A. S. El-Dakhs, "Comparative genre analysis of research article abstracts in more and less prestigious journals: linguistics journals in focus," Research in Language, vol. 16, no. 1, pp. 47-63, 2018.

[3] W. Suntara and S. Usaha, "Research article abstracts in two related disciplines: rhetorical variation between linguistics and applied linguistics," English Language Teaching, vol. 6, no. 2, pp. 84-99, 2013.

[4] P. D. Phuong Dzung Pho, "Research article abstracts in applied linguistics and educational technology: a study of linguistic realizations of rhetorical structure and authorial stance," Discourse Studies, vol. 10, no. 2, pp. 231-250, 2008.

[5] P. Brett, "A genre analysis of the results section of sociology articles," English for Specific Purposes, vol. 13, no. 1, pp. 47-59, 1994.

[6] T. Huckin, "Abstracting from abstracts," in Academic Writing in Context, M. Hewings, Ed., pp. 93-103, Continuum, London, UK, 2006.

[7] H. Ren and Y. Li, "A comparison study on the rhetorical moves of abstracts in published research articles and master's foreign-language theses," English Language Teaching, vol. 4, no. 1, pp. 162-166, 2011.

[8] J. Flowerdew, "Scholarly writers who use English as an Additional Language: what can Goffman's "Stigma" tell us?"
Journal of English for Academic Purposes, vol. 7, no. 2, pp. 77-86, 2008.

[9] P. Supranont, "Developing a writing template of research article abstracts: a corpus-based method," Procedia-Social and Behavioral Sciences, vol. 66, pp. 144-156, 2012.

[10] G. Tankó, "Literary research article abstracts: an analysis of rhetorical moves and their linguistic realizations," Journal of English for Academic Purposes, vol. 27, pp. 42-55, 2017.

[11] K. Hyland, Academic Discourse, Continuum International Publishing, GBR, London, UK, 2009.

[12] H. Marefat and S. Mohammadzadeh, "Genre analysis of literature research article abstracts: a cross-linguistic, crosscultural study," Applied Research, vol. 2, no. 2, pp. 37-50, 2013.

[13] F. Kaya and O. Yağiz, "Move analysis of research article abstracts in the field of ELT: a comparative study," Dil Ve Dilbilimi Çalışmaları Dergisi, vol. 16, no. 1, pp. 390-404, 2020.

[14] B. Seidlhofer, Approaches to Summarization: Discourse Analysis and Language Education, Vol. 11, Gunter Narr Verlag, Tübingen, Germany, 1995.

[15] J. M. Swales, Genre Analysis: English in Academic and Research Settings, CUP, Cambridge, UK, 1990.

[16] V. K. Bhatia, Analyzing Genre: Language Use in Professional Settings, Longman Publishing, New York, NY, USA, 1993.

[17] M. B. Dos Santos, “The textual organization of research paper abstracts in applied linguistics," Text - Interdisciplinary Journal for the Study of Discourse, vol. 16, no. 4, pp. 481-499, 1996.

[18] K. Hyland, Disciplinary Discourses: Social Interaction in Academic Writing, Pearson, London, UK, 2000.

[19] B. Ghasempour and M. Farnia, "Contrastive move analysis: Persian and English research article abstracts in law," The Journal of Teaching English for Specific and Academic Purposes, vol. 5, no. 4, pp. 739-753, 2017.

[20] W. Amnuai, "Analyses of rhetorical moves and linguistic realizations in accounting research article abstracts published in international and Thai-based journals," SAGE Open, vol. 9, no. 1, pp. 1-9, 2019.

[21] B. Behnam and J. Zamanian, "Genre analysis of Oxford and Tabriz applied linguistics research article abstracts: from move structure to transitivity analysis," The Journal of Applied Linguistics, vol. 6, no. 12, pp. 41-59, 2013.

[22] S. Saeeaw, Genre analysis of rhetorical variation between environmental science and applied linguistics, Thammasat University, Unpublished PhD Dissertation, Language Institute, 2014.

[23] H. M. Sidek, N. S. Mat Saad, H. Baharun, and M. M. Idris, "An analysis of rhetorical moves in abstracts for conference proceedings," IJASOS- International E-Journal of Advances in Social Sciences, vol. 2, no. 4, pp. 24-31, 2016.

[24] A. M. Darabad, "Move analysis of research article abstracts: a cross-disciplinary study," International Journal of Linguistics, vol. 8, no. 2, pp. 125-140, 2016.

[25] M. R. Atai and P. Habibie, "Genre analysis of applied linguistics research article introductions: exploring sub-disciplinary variations," Taiwan International ESP Journal, vol. 4, no. 1, pp. 25-44, 2012. 